\title{
Study on the Decoration Culture of Paper Cuttings and Decals of Ceramics in Jizhou Kiln
}

\author{
Huiming $\operatorname{Pan}^{1, *}$ \\ ${ }^{1}$ Jingdezhen Ceramic University, Jingdezhen, Jiangxi, China \\ *Corresponding author. Email:3106426835@qq.com
}

\begin{abstract}
Paper cuttings and decals are one of the unique craft of ceramic decoration in Jizhou Kiln. Previous studies only focused on the decorative forms and styles of paper cuttings and decals, but didn't study the reasons for the formation of such unique decorative forms and styles. Therefore, this article explains the changes in the paper cuttings and decals craft of Jizhou Kiln, and draws a comprehensive conclusion from its cultural phenomenon causes (the integration of the technology of the northern people's south migration, the emotional memory of the northern people's south migration to their hometown, the handicraft relationship with the Song Dynasty society, the relationship with the Song Dynasty's literati tea fighting, and the relationship with the Zen culture) that the cultural phenomenon of the ceramic decoration craft of Jizhou Kiln paper cuttings and decals is the result of the integration, dissemination and creation of various cultures in the process of ethnic migration.
\end{abstract}

Keywords: Jizhou Kiln, Ceramic decoration, Paper cuttings and decals, Decoration culture.

\section{INTRODUCTION}

There are many types of ceramic decoration crafts in Jizhou Kiln, and "paper cuttings and decals" are one of the more typical decoration crafts. The emergence of "paper cuttings and decals" is closely related to the lives of ceramic craftsmen. They have a dual craft identity, namely, the embodiment of paper cutting craft as well as the embodiment of ceramic craft. As a southern kiln, why does Jizhou Kiln have paper cutting techniques with northern customs? And why can this craft exist in a new form and be passed down from generation to generation in the ceramic decoration of Jizhou Kiln in the south? If only from the characteristics of paper, the existence of paper is short-lived, because paper can't withstand the baptism of water and fire, nor can it withstand longterm natural erosion and weathering; however, after special ceramic processing technology, it has a wonderful connection with ceramics, which can transform its own properties from short-lived to eternal, and remain in the world for a long time. From the paper that is easily torn to the ceramic that is impermeable to water and fire, it is not only the surface presentation of the physical reaction between paper and ceramic, fundamentally, the physical transformation of paper into ceramic is actually the preservation and evolution of potters' personal memories. From the short-lived to the permanent end, it is to let future generations remember the root of culture after all. After the fusion of paper cutting culture and ceramic culture, and the fusion of northern culture and southern culture, the final Jizhou Kiln paper cutting and decal ceramic is not only the memory root of northerners, but also the memory root of southerners. Because it is not only the fusion of the physical state, the cultural state, the reproduction of northerners and southerners, and the spread and implantation of culture are already integrated.

This article explores the root cause of this ceramic decoration culture from the ceramic paper cutting and decal decoration craft of Jizhou Kiln. The ceramic paper cutting and decal technique of Jizhou Kiln is not only a technique passed down from generation to generation by the craftsmen of Jizhou Kiln, but also a living presentation of local craftsmen. It is the proof of space and time. In addition to the long nostalgia of the northern potters, until the cultural integration, it also became the homesickness of mutual dependence and integration of the north and south cultures, because 
it eventually formed the unique ceramic culture of Jizhou Kiln.

\section{THE TECHNIQUE OF JIZHOU KILN PAPER CUTTING AND DECAL}

The earliest paper cutting ceramic decoration patterns in China came from the Tang Dynasty's ceramic paper cutting decorative ewer unearthed successively in Hebei Province. Its paper cutting decoration was used on ceramics earlier than the Jizhou Kiln ${ }^{1}$. However, the ceramic paper cutting and decal decoration techniques of these three ewers are relatively simple, not as rich as the Jizhou Kiln. There are two methods for making paper cutting and decal decoration craft in Jizhou Kiln:

\subsection{Production Method}

There are two methods commonly used in the paper cutting and decal craft of Jizhou Kiln: the first is the monochrome glaze decoration method. The Tang Dynasty's ceramic paper cutting decorative ewers discovered successively unearthed in Hebei Province also used this method. The materials for paper cutting must be prepared in advance. After the paper is cut, the potter save it for later use, and pasted it directly on the carcass of the utensil to be decorated. At this time, the paper cutting covered the beige carcass. Next, glazing was performed with mainly black glaze. After the glaze layer was dry, the potter removed the paper cutting; except for the exposed part of the paper cutting, the carcass was black, and the exposed part of the paper cutting pattern was the beige color of the carcass.

The second method is the two-color glaze decoration method. The potter first put a layer of black glaze on the carcass, then pasted the paper cutting on the black glaze, and then sprayed another layer of glaze on the paper cutting. At this time, the glaze color could be different from black. After the paper cutting was removed, the first layer of black was exposed. In the kiln fire, the two glaze colors merged together to form a rich color, and they would undergo kiln changes in the kiln with various color levels. And the exposed part covered by the paper cutting was still black. This form of twocolor glaze is often used. The glaze color of Jizhou Kiln is rich, and there are more choices, which

1. Mu Qing. New Proof of Paper Cutting and Decal Porcelain [J]. Wenwu Chunqiu. Supplement of 1997. Total No. 38. P44-P46. provide more possibilities for the paper cutting and decal decoration craft of Jizhou Kiln.

\subsection{The Form and Theme of Paper Cutting}

The paper cutting and decal craft of Jizhou Kiln is not only based on paper cutting, paper carving is also one of the craft and techniques. The difference is that paper carving is more expressive for fine patterns, and the material of paper cutting is simpler than that of paper carving. Therefore, the paper cutting and decal process of Jizhou Kiln adopts the method of combining cutting and carving ${ }^{2}$.

The paper cuttings in the Jizhou Kiln paper cuttings and decals are similar to the northern folk paper cuttings, but there is still a certain difference for ceramic decoration. Because the surface of ceramic implements is relatively small, some paper cuttings that are too fine will become blurred or even disappear due to the flow of the glaze when they are fired. The hollow details to be expressed will disappear due to the flow of the glaze, so the craft of paper cutting also needs to be exquisite. The paper cutting style of Jizhou Kiln is generally exaggerated, concise, simple, and vivid. The paper cutting style is mainly independent paper cutting and symmetrical paper cutting. There are patterns of two-dimension series as well as four-dimension series. Moreover, the general form of paper cutting perspective is mainly plane, but in fact, the performance of decorative ceramics is curved, so paper cutting will produce different angles of perspective on ceramics, and this kind of perspective will make paper cutting more threedimensional. The patterns of Jizhou Kiln paper cuttings and decals are mostly related to folk auspicious dragons and phoenixes, flowers and birds, butterflies, and plum blossom branches. There are also direct decorations of auspicious sentences, symbolizing happiness. The image is vivid and simple.
2. Liu Pinsan. Paper-cutting Patterns of Jizhou Kiln Porcelain [J]. Relics Form South. 1997.01. P102-107. 


\section{EXPLORATION OF THE CRAFT CULTURE OF JIZHOU KILN PAPER CUTTINGS AND DECALS}

\subsection{Jizhou Kiln Ceramic Paper Cutting and Decal Craft Originated from the Technical Integration of the Northern People's South Migration}

Latzel is a famous geographer in Germany. He is a pioneer of diffusionism. He believes that certain cultural elements are diffused through ethnic migration. German, Austrian, and British scholars who share the same "diffusionism" theory with him also agree that space is an element of cultural research, and similar cultures are spread to various places after they are produced in a certain place $^{3}$. Jizhou Kiln originated in the late Tang Dynasty, developed after the Northern Song Dynasty, and prospered in the Southern Song Dynasty. Due to the war in the north, the northerners moved south, and the potters from the north also moved into the Jizhou Kiln in Jiangxi to continue their ceramic work. The move of the northern people to the south not only brought ceramic skills, but also brought culture into it. And the resulting paper cutting craft and culture that originally appeared on northern festivals were incorporated into the ceramic firing of Jizhou Kiln by northern craftsmen, forming a unique blend of north-south culture and craft, and having a style of its own in Jizhou Kiln.

\subsection{The Spiritual Culture of Jizhou Kiln Ceramic Paper Cutting and Decal Decoration Craft Originated from the Homesickness of the Northerners After They Moved South}

Potters who were far from home were displaced. In an unfamiliar environment, they missed their hometown. The festive paper cutting culture was a nostalgia and emotional sustenance for their hometown. But the flimsy paper disappeared faster than the heaviness of homesickness. How could these emotions be firmly remembered? The transition from transience to eternity became a contract between paper and ceramics. The wise potters permanently engraved heavy memories on the ceramics used daily. This became a spiritual sustenance that could comfort the homesickness of

3. Tian Zhaoyuan. Cultural Anthropology Course [M]. Shanghai: East China Normal University Press, 2005.12.P55 the potters in the north at any time, and it was also an important form of nostalgia. At this time, the ceramics with the paper cutting and decal decoration craft is not only a substance, but also a spiritual sustenance. Perbrier proposed that, relative to the shape of an object, the memory of an object is more important than its appearance ${ }^{4}$. And the paper cutting and decal decoration craft of Jizhou Kiln was produced because of the memory of the hometown after the northerners moved south, and the value of such implements far exceeded its own price.

\subsection{The Relationship Between the Decoration Craft of Jizhou Kiln Ceramic Paper Cuttings and Decals and the Handicraft Industry in Song Dynasty Society}

The society in which Jizhou Kiln lived in the Song Dynasty was a prosperous society. Under the conditions of political, social, and economic stability, the handicraft industry was also very developed. In addition to the ceramic industry, the paper industry, textile industry, wood carving industry and other handicraft industries were all prosperous. So there was no shortage of skilled craftsmen in paper cutting. These industries influenced each other, and the craft culture merged with each other. The flourishing paper industry provided a medium for paper cutting. The wood carving industry and the paper cutting craft were similar, and there were occasional crossovers and exchanges between the craftsmen.

\subsection{The Relationship Between the Decoration Craft of Jizhou Kiln Ceramic Paper Cuttings and Decals and the Tea Fighting Culture of Song Dynasty}

The Song Dynasty inherited the tea-drinking habits of the literati in the Tang Dynasty, and the tea culture prevailed. The huge class of scholarofficials praised tea culture as an exquisite and restrained form of literati tea fighting. Tea drinking and tea fighting tea became a hobby among literati. The implements used in tea fighting were regarded beautiful in black. The standard of tea fighting was to judge the winner or loser by the length of time, brightness and concentration of the white foam

4. (British) Anna Moran, (British) Sorcha O'Brien. Zhao Chengqing, Lu Kai trans. [M]. Nanjing: Jiangsu Phoenix Fine Arts Publishing House, 2020.8.P2. 
floating in the cup. And the black color could best show the white foam raised in the tea, so the unique aesthetic style of taking black as the beauty made black porcelain develop rapidly in the Song Dynasty. Among them, the ceramic paper cutting and decal decoration of Jizhou Kiln was decorated with black glaze, and the elegant paper cutting style became an interesting tool for tea fighting, which made the paper cutting and decal craft of Jizhou Kiln more refined.

\subsection{The Relationship Between Zen Culture and Jizhou Kiln Paper Cutting and Decal Decoration Craft}

Jizhou Kiln paper cuttings and decals belonged to a ceramic decoration craft in the Jizhou Kiln black-glazed porcelain series. Buddhism prevailed in the Tang Dynasty, and Zen culture had a great influence. The famous Qingyuan Mountain in China has become one of the most influential Buddhist districts for a long time. With the rise of temples, Zen culture became the mainstream at the time, and Zen and tea culture also became popular. The black-glazed porcelain of Jizhou Kiln was in line with the aesthetics of Zen and tea culture. Chinese Theory of Color is based on the Theory of Yin and Yang and Theory of Five Elements. Black is the most mysterious color and can best express the spirit of oriental aesthetics. Because of the subconsciousness of national psychology, black has formed a unique Zen aesthetic orientation and symbol.

\section{CONCLUSION}

As a British diffusionism believer, Pitt-Rivers believes that the main driving force of the power of human progress comes from the cultural integration and connection of various ethnic groups ${ }^{5}$. The migration of northerners to the south was the inducement of social and cultural changes in Jizhou Kiln. The birth of Jizhou Kiln ceramic paper cutting and decal decoration craft culture came from the feeling of missing of the northern potters moving south to their hometown. It was a material created by the combination of north and south cultures, and it was the presentation of the techniques and spirit of the potters of the north and south; compared to the ceramic itself, its modes of presentation had more humanistic and spiritual value. The paper cutting and decal decoration craft of Jizhou Kiln

5. Tian Zhaoyuan. Cultural Anthropology Course [M]. Shanghai: East China Normal University Press, 2005.12.P57 was created during such cultural changes, and it was also the result of cultural dissemination and the intersection of cultural circles. It added regional uniqueness to the original rich ceramic decoration. If the early Jizhou Kiln ceramic paper cutting and decal decoration craft contained only the feelings and thoughts of the potters who moved from the north to the south and far away from their hometowns for their hometowns, in the later period, cultures merged with each other, and this paper cutting culture collided with the local regional culture to create new decorations and emotions, then the ceramic culture of Jizhou Kiln in this period became the new ceramic culture of Jizhou Kiln. Culture is always influencing, disseminating, and continuously changing. After leaving Jizhou Kiln, the paper cutting and decal ceramic became the homesickness of the locals of the Jizhou Kiln. Fortunately, this kind of homesickness was permanently fixed on the ceramic. And the prosperity of the ceramic paper cutting and decal decoration craft of Jizhou Kiln was not only because of the fusion of cultures and techniques due to the nostalgia of the northerners, but also due to the development of the social handicraft culture in the Song Dynasty, the prosperity of the teafighting culture of literati, and the influence of Zen culture and so on. After all, the appearance of this kind of decoration craft is the product of the integration of multi-culture and spirit, and it is a manifestation of the regionality of national culture, embodying the deepest regional ceramic cultural character.

\section{AUTHORS' CONTRIBUTIONS}

This paper is independently completed by Huiming Pan.

\section{REFERENCES}

[1] (British) Anna Moran, (British) Sorcha O'Brien. Zhao Chengqing, Lu Kai trans. [M]. Nanjing: Jiangsu Phoenix Fine Arts Publishing House, 2020.8 (in Chinese)

[2] Zhao Xuefeng, Zu Shaoying. Analysis of the Possibility Factors of the Phenomenon of Population Migration in the Two Song Dynasties on the Cultural Exchange Between Cizhou Kiln and Jizhou Kiln and Other Kiln Mouths [A]. Zhang Xiaoyan, Zhang Guoying. Collected Works of the Fifth International Cizhou Kiln Forum [C]. Beijing: Cultural Publishing House, 2020.1.p13-14. (in Chinese) 
[3] Liu Xiaoyu. Jizhou Kiln [M]. Harbin: Heilongjiang Fine Arts Publishing House, 2017.06. (in Chinese)

[4] Gong Yu, Lu Meina. On the Paper Cuttings and Decals of Jizhou Kiln Black-glazed Porcelain [J]. China Market, 2014, 12. (48): 82-83. (in Chinese)

[5] Tian Zhaoyuan. Cultural Anthropology Course [M]. Shanghai: East China Normal University Press, 2005.12 (in Chinese)

[6] Liu Pinsan. Paper-cutting Patterns of Jizhou Kiln Porcelain [J]. Relics Form South. 1997.01. P102-107. (in Chinese) 